\title{
SPATIOTEMPORAL CHANGES IN VELOCITY OF MELLOR GLACIER, EAST ANTARCTICA USING LANDSAT-8 DATA
}

\author{
Prashant H. Pandit ${ }^{1}$, U. Khot ${ }^{2}, *$, S. D. Jawak ${ }^{3,4}$, A. J. Luis ${ }^{4}$ \\ ${ }^{1}$ Department of Natural Resources, TERI University, New Delhi - 110 070, India; sh.prashantpandit@ gmail.com \\ ${ }^{2}$ Symbiosis Institute of Geoinformatics, Symbiosis International University, Pune, Maharashtra, 411005; utkash.khot11@ gmail.com \\ ${ }^{3}$ Svalbard Integrated Arctic Earth Observing System (SIOS), SIOS Knowledge Centre, University Centre in Svalbard \\ (UNIS), P.O. Box 156, N-9171, Longyearbyen, Svalbard, Norway; shridhar.jawak@ gmail.com \\ ${ }^{4}$ Earth System Science Organization-National Centre for Antarctic and Ocean Research, Ministry of Earth Sciences, Government \\ of India, Headland Sada, Vasco-da -Gama, Goa 403804, India; alvluis@ ncaor.gov.in
}

\section{Commission V, SS: Utilization of Bio-Resource National Databases}

\begin{abstract}
KEY WORDS: Glacier Velocity, Image Matching, Antarctic
\end{abstract}
\begin{abstract}
:
Glaciers all over the world are experiencing changes at varying stages due to changing climatic conditions. Minuscule changes in the glaciers in Antarctica can thus have major implications. The velocity of glaciers is important in several aspects of glaciology. A glacier's movement is caused by different factors such as gravity, internal deformation present in the ice, pressure caused by accumulation of snow, basal sliding etc. The velocity of a glacier is an important factor governing mass balance and the stability of the glacier. A glacier which moves fast generally brings more ice towards the terminus than a slow moving glacier. Thus, the glacier velocity can determine its load carrying capacity and gives indication on the 'health' of the glacier. Measurement of the ice flow velocity can help model glacier dynamics and thus provide increasing insights on different glacier subtleties. However, field measurements of velocity are limited in spatial and temporal domains because these operations are manual, tedious and logistically expensive. Remote sensing is a tool to monitor and generate such data without the need for physical expeditions. This study uses optical satellite imagery to understand the mechanisms involved in the movement of a glacier. Optical image correlation method (COSI-Corr module) is chosen here as the promising method to derive displacement of a moving glacier. The principle involved in this technique is that two images acquired at different times are correlated to find the shift in the position of moving ice, which is then treated as displacement in the time interval. Employing this technique we estimated the velocity of Mellor glacier $\left(73^{\circ} 30^{\prime} \mathrm{S}, 66^{\circ} 30^{\prime} \mathrm{E}\right)$, a tributary glacier of the Amery Ice Shelf, Antarctica, over a span of four years from 2014 to 2017. Correlation is performed using Landsat- 8 panchromatic images of 15 m resolution. Optical images from Landsat 8 often have noise due to atmospheric conditions such as cloud cover, so we used only those images cloud with cloud cover less than $10 \%$. The glacier is covered in 128 path frame and 112 by Landsat- 8 . The correlation frequency was calculated using the correlator engine. Window size taken here is 256 and step sizes is 64 for both $\mathrm{x}$ and $\mathrm{y}$ dimensions. Once the correlation is calculated for an image pair for a specific time-period, we obtain three different outputs. Two of them indicated displacement (one in $\mathrm{x}$ direction and another in y direction) and the remaining output provided signal to noise ratio. The band math tool using displacement outputs in ENVI software performed velocity calculations. This gives us a raster image showing velocity at each point or pixel. Some errors such as noise persist and their correction is performed in ArcGIS software. In order to get pure signals, we removed all the signals with a signal to noise ratio less than 0.9 and this was carried out using raster calculator tool. All the resultant velocity rasters were interpolated and bias was calculated between seasons of two consecutive years. Two maps were generated for each year, one for early summer i.e. from January to April and one from September to December using the resultant velocity raster. The mean values of velocities found for Mellor glacier from Jan-April 2014, 2015,2016 and 2017 were $374.06 \mathrm{ma}^{-1}, 413.59 \mathrm{ma}^{-1}, 278.62 \mathrm{ma}^{-1}$ and $406.66 \mathrm{ma}^{-1}$, respectively. Velocities for September-December 2014, 2015,2016 and 2017 were found to be $334.63 \mathrm{ma}^{-1}, 334.43 \mathrm{ma}^{-1}, 367.37 \mathrm{ma}^{-1}$ and $381.31 \mathrm{ma}^{-1}$, respectively. The biases are computed for all the seasons of four years and root mean square (RMSE) values are estimated. These RMSE values signify the season-wise variations in the velocities. RMSE values for season of Jan-April 2014-15, 2015-16 and 2016-17 were 75.92 $\mathrm{ma}^{-1}, 147.82 \mathrm{ma}^{-1}$, and $133.33 \mathrm{ma}^{-1}$, respectively. Similarly, RMSE values for season of September-December 2014-15, 2015-16 and 2016-17 are $35.7 \mathrm{ma}^{-1}, 51.29 \mathrm{ma}^{-1}$ and $35.84 \mathrm{ma}^{-1}$ respectively. The results showed variations in velocities for different seasons. We plan to integrate this data with the discharge rates, to estimate mass balance and melting rates of the glacier to decipher mechanisms at work for the Mellor glacier.
\end{abstract}

\section{INTRODUCTION}

The velocity of a glacier can be found either by performing image-matching techniques or by DInSAR. Both of these methods complement each other in the study of glaciology. It is also a critical variable in understanding glacier dynamics. The method of image matching involves finding the extent of correlation between two images. This can be based on area taken as a whole or on extraction of specific common features from images. Both the images in the pair must capture the same area to be useful for such a study. These images are to be taken from two different time spans so that changes can be detected within the extracted features for which the images are being correlated. Feature tracking operates by tracing of the movements of recognisable objects within the images, which are co-registered and sequential. This helps in deriving a two-dimensional velocity field. This was first applied to optical Landsat TM images only (Schubert et. al., 2013). In addition to optical images, radar and digital elevation models can be used for the image matching technique (Pandit et al., 2017). While the pixel tracking method

\footnotetext{
* Corresponding author.
} 
is used for estimating the velocity of glaciers, the time gap between the images should be large enough to detect some substantial changes. The accuracy of the resultant velocity estimated by this technique is based on the resolution of the images, temporal difference, melting/ablation, strain component and as we are using optical satellite imagery in this study, atmospheric conditions are also vital. Even the availability of the data is not an issue for optical images; however, obtaining cloudfree data is important. Radar images do not have this problem as it penetrates cloud cover but the historic availability of radar data is only recent (Pandit et al., 2018). The problem with DEMs is that water absorbs the laser. Therefore, the use of DEMs has least preference. The COSI-Corr module in ENVI software is developed for correlation of optical images, and detection of ground deformation. It is considered as the most suitable way of deriving velocity of glaciers all over the globe (Heid, 2011). COSI-Corr is advantageous because of the availability of a large amount of optical remote sensors, rich data sources and longer time series. Hence, it is more suitable than SAR monitoring methods for estimating velocities and spatio-temporal variations for longer periods. The advantage of moderate resolution images such as Landsat is that the coverage of a single image is broad enough to avoid errors in correlation, large fields of view help to acquire image of same area over several times thereby selection of images with minimum cloud cover is possible (Chen et al., 2014). DInSAR method is based on calculations of phase differences. For that, the phase has to be coherent between two acquisitions. Therefore, the time span over which displacement is calculated is restricted to few days or up to a month (Heid, 2011). The important advantage of DInSAR is that it is not dependent on physical features but only on phase differences. Change detection in velocities can play a vital role in the understanding of overall glacier dynamics in the Antarctic region. The changes or deformations of a glacier along with its motion are considered as indications of its life. A glacier's movement takes place over large span of time. Observations on long-term changes seen in a particular area is thus an important aspect. This study focuses on estimation of velocity of the Mellor glacier in East Antarctica, and the detection of spatiotemporal (seasonal) changes in it.

\section{STUDY AREA}

The study area taken into consideration is Mellor glacier (Figure 1), a tributary glacier of the Amery Ice Shelf located in East Antarctica. It has the latitude of $73^{\circ} 42^{\prime} 19^{\prime \prime}\left(73.7053^{\circ}\right)$ south and longitude of $66^{\circ} 3^{\prime} 19^{\prime \prime}\left(66.0553^{\circ}\right)$ east.

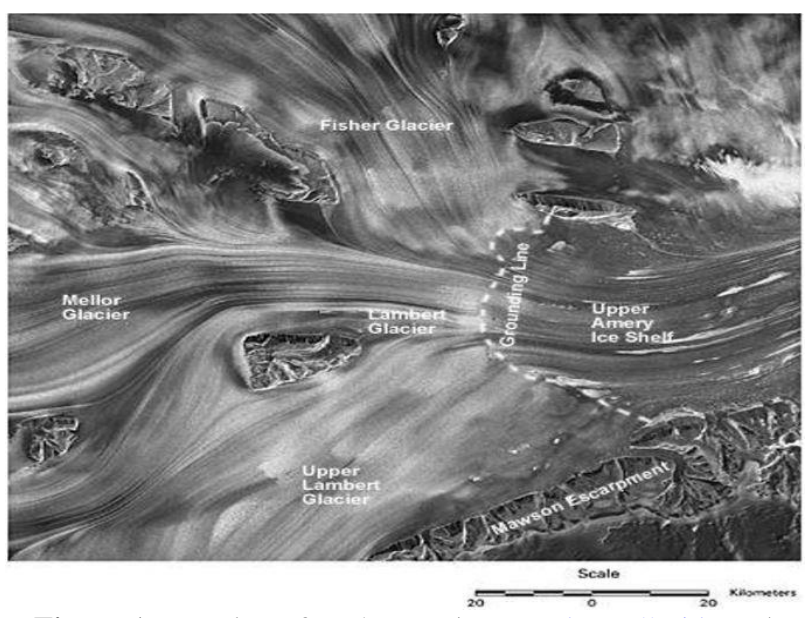

Figure 1. Location of study area (source: $h$ ttps://nsidc.org)
The area covered by the glacier is around 457,396 sq. km. Mellor glacier is the second largest glacier with a fast-moving area of 6000 sq. km. Its flow velocity reaches $855 \mathrm{~m} / \mathrm{y}$ at confluence zone. It has an elevation of about $736 \mathrm{~m}$ above sea level. It flows northwest between mount Maguire and Mount Newton. It coalesces with Collins glacier before the junction of Lambert glacier.

\section{METHODOLOGY}

The protocol has been divided into three parts, 1) Selection of data 2) Application of feature tracking method and 3) Change detection.

\subsection{Data selection}

Calculation of correlation requires two images. The images are taken such that the texture of the glacier's surface is visible in it, accurate geographic coordinates of the captured area are known and resolution is good enough to obtain the displacement of the glacier (Chen et al., 2014). Band 8 data (panchromatic images) from the Landsat 8 satellite are used here. It provides $15 \mathrm{~m}$ of spatial resolution. In order to avoid errors caused by cloud cover, only those images were chosen where cloud cover was less than $10 \%$. The Mellor glacier has been covered in 128-path frame and 112 row by Landsat- 8 . Here we are detecting spatiotemporal changes for four consecutive years from 2014 to 2017. In Antarctica, we have early summer and late summer. Early summer lasts from January to April and late summer lasts from September to December. Data is not available during Antarctic winters as there is no sunlight. Therefore, two images from each season are taken for correlation.

\subsection{Feature tracking method}

As we have two images from one season, the early image will be the master image and the later image will be the slave image. The master image is divided into a number of grids. The window that slides over the images in order to correlate them is measured in pixels. Here the window size is taken as 256 in both $\mathrm{x}$ and $\mathrm{y}$ dimension. The step size for a window is taken as 64. Crosscorrelation calculation is performed after grid segmentation. The results of correlation are saved as displacement in $\mathrm{x}$, y-direction as well as in the form of signal to noise ratio. All these three outputs are saved in raster formats. Temporal differences between two images are known, hence with the resultant displacement, we obtain velocity.

\section{RESULTS}

Biases are found within velocity data sets for Mellor glacier with respect to the period for which we are tracking spatiotemporal variations. Bias gives us the differences in expected results. Here, we simply subtract the two respective velocity raster files to find bias. Root mean square or RMS value is then obtained from it, which shows how significantly velocity has changed throughout the different periods. To find seasonal variations, bias needs to be calculated between two images from the same season but of two different years. For example, here two seasons are considered within a year that is early summer season (Jan to April) and late summer (September to December).

\begin{tabular}{|c|c|}
\hline Period & $\begin{array}{c}\text { Mean Velocity } \\
(\mathbf{m} / \text { year })\end{array}$ \\
\hline Jan-April 2014 & 374.04 \\
\hline Sept- December 2014 & 334.63 \\
\hline
\end{tabular}




\begin{tabular}{|c|c|}
\hline Jan-April 2015 & 413.49 \\
\hline Sept- December2015 & 334.43 \\
\hline Jan-April 2016 & 278.62 \\
\hline Sept- December2016 & 367.37 \\
\hline Jan-April2017 & 406.66 \\
\hline Sept- December2017 & 381.31 \\
\hline
\end{tabular}

Table 1. Mean velocities for each season from 2014 to 2017

\begin{tabular}{|c|c|}
\hline Period & RMSE (m/year) \\
\hline Jan-April 2014-2015 & 75.92 \\
\hline Sept-December 2014-15 & 35.7 \\
\hline Jan-April 2015-16 & 147.82 \\
\hline Sept-December 2015-16 & 51.29 \\
\hline Jan-April 2016-17 & 133.33 \\
\hline Sept-December 2016-17 & 35.84 \\
\hline
\end{tabular}

Table 2. Seasonal changes

Table 2 shows the spatiotemporal changes in Mellor glacier from 2014-2017.

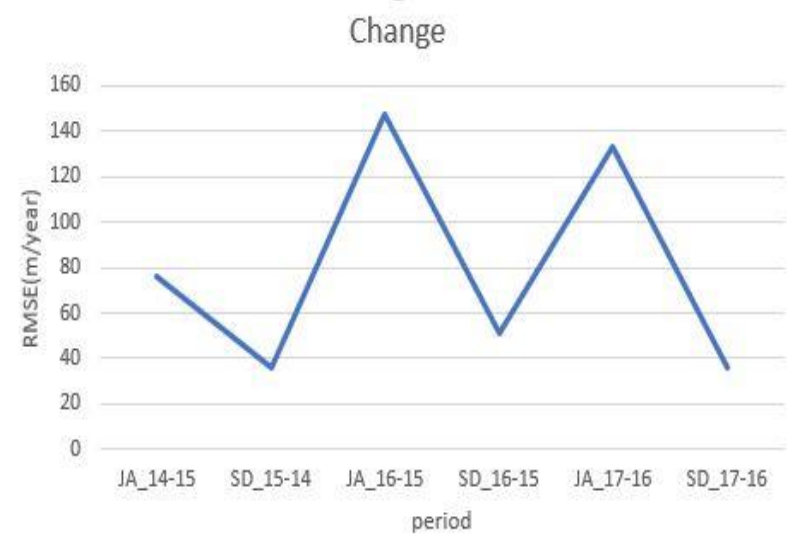

Figure 2. Graph showing spatiotemporal changes in velocity.

\section{CONCLUSION}

The main focus of this work was to develop feature tracking (or image matching) technique in the field of glaciology. The velocity dimensions are calculated by using satellite images and are accurate enough to monitor the overall changes in the study area here, Mellor glacier. All the results obtained in the form of velocity raster are interpolated further. The maps have been validated by comparing them with MEaSUREs data provided by National Snow \& Ice Data Centre (NSIDC). Stable data set for four consecutive years from 2014 to 2017 is generated. To conclude we can say that COSI-Corr module is one of the strongest GIS or remote sensing tool to accomplish in-depth and synoptic assessment (comparison) of glacier dynamics. Analysis done here suggests that image matching technique using correlation operator with the combination of optical imagery is a much appropriate methodology for deriving precise and costeffective surface velocity measurements. On the basis of this spatiotemporal changes in the Mellor glacier are detected.

\section{ACKNOWLEDGEMENTS}

The authors would like to thank USGS-Earth explorer for providing the imagery used in this study. We also acknowledge Dr. Rajan, former Director, ESSO-NCAOR and Dr. M. Ravichandran, Director-in-charge, ESSO-NCAOR, for their encouragement and motivation for this research. The entire experiment, validation, manuscript preparation, and editing of the manuscript was conducted at the ESSO-NCAOR. The lead author (S.D.J) has recently moved to the SIOS, Longyearbyen, Norway.

\section{REFERENCES}

Chen, J., Ke, C. Q., \& Shao, Z. D., 2014. Spatiotemporal variations in the surface velocities of Antarctic Peninsula glaciers. https://doi.org/10.5194/tcd-8-5875-2014

Heid, T., 2011. Deriving glacier surface velocities from repeat optical images.

Available at: https://www.duo.uio.no/handle/10852/12336 (accessed on 20 July 2018).

Pandit, P.H, Jawak, S.D and Luis, A., 2017. 38th Asian Conference on Remote Sensing (ACRS 2017): Space Applications: Touching Human Lives. In: ACRS. [online] Asian Association on Remote Sensing (AARS).

Available at: http://a-a-r-s.org/acrs/index.php/acrs/acrsoverview/proceedings 1 ?view $=$ publication $\&$ task $=$ show $\&$ id $=311$ 0 (accessed on 02 July 2018).

Pandit, P.H., Jawak, S.D. and Luis, A.J., 2018. Estimation of Velocity of the Polar Record Glacier, Antarctica Using Synthetic Aperture Radar (SAR). In Multidisciplinary Digital Publishing Institute Proceedings, 2 (7), 332. https://doi.org/10.3390/ecrs-2-05145

Schubert, A., Faes, A., Kääb, A., \& Meier, E., 2013. Glacier surface velocity estimation using repeat TerraSAR-X images : Wavelet- vs . correlation-based image matching. ISPRS Journal of Photogrammetry and Remote Sensing, 82, 49-62. https://doi.org/10.1016/j.isprsjprs.2013.04.010 